\title{
Effect of the IGF-1/PTEN/Akt/FoxO signaling pathway in the duodenal mucosa of rats subjected to water immersion and restraint stress
}

\author{
P. Huang ${ }^{1,2}$, Z.R. Zhou ${ }^{1}$, M.Q. Zheng ${ }^{1}$ and F.X. Shi ${ }^{1}$ \\ ${ }^{1}$ Laboratory of Animal Reproduction, College of Animal Science and Technology, \\ Nanjing Agricultural University, Nanjing, China \\ ${ }^{2}$ Department of Pathology, School of Medical Science and Laboratory Medicine, \\ Jiangsu University, Zhenjiang, China \\ Corresponding author: F.X. Shi \\ E-mail: fxshi@njau.edu.cn / njauhp@gmail.com
}

Genet. Mol. Res. 11 (4): 4775-4788 (2012)

Received January 24, 2012

Accepted May 29, 2012

Published September 19, 2012

DOI http://dx.doi.org/10.4238/2012.September.19.2

\begin{abstract}
The insulin growth factor $1 /$ phosphatase and tensin homologue deleted on chromosome 10/Akt/forkhead box (IGF-1/PTEN/ $\mathrm{Akt} / \mathrm{FoxO}$ ) signaling pathway reportedly exhibits gastroprotective effects by reducing water immersion and restraint stress (WRS)-induced gastric mucosal cell apoptosis. We examined the expression and localization of IGF-1, PTEN, Akt, and FoxO proteins, caspase-3 activity, and the number of apoptotic cells in the duodenal mucosa of rats subjected to WRS to confirm whether the IGF-1/PTEN/Akt/FoxO signaling pathway has a role in the duodenal mucosa. The results indicated that WRS enhanced cell apoptosis in the duodenal mucosa. In addition, in normal rats, PTEN was found mainly in the cellular cytoplasm of the duodenal glands and lamina propria of villi. IGF-1 and total Akt were observed in the cellular cytoplasm of the duodenal glands. In addition, total Akt was found in the cellular cytoplasm of the myenteric plexus. FoxO3a and FoxO4 were primarily concentrated in the cellular cytoplasm of the lamina propria. Specifically, PTEN, FoxO3a and FoxO4 were also localized in the cellular cytoplasm of lamina propria of restituted villi in
\end{abstract}


the duodenal mucosa of rat subjected to WRS. In addition, messenger RNA transcript levels of IGF-1, PTEN, Akt1, Akt2, FoxO3, and FoxO4 were upregulated in the duodenal mucosa, with a peak between the 4th and 8th day after $7 \mathrm{~h}$ of WRS. Furthermore, the results also suggested that $A k t 3$ messenger RNA transcript levels in the duodenal mucosa of rats after WRS showed no significant differences compared with those in the non-WRS group. Collectively, our results implied that the IGF-1/ PTEN/Akt/FoxO signaling pathway was effective in regulating cellular apoptosis in the duodenal mucosa of rats after WRS.

Key words: IGF-1; FoxO; Signaling pathway; Duodenum; Rat

\section{INTRODUCTION}

The water immersion and restraint stress (WRS) rat has consistently been used as an animal model of gastroduodenal mucosal lesions (Wang and Johnson, 1991; Adachi et al., 2011). The insulin growth factor $1 /$ phosphatase and tensin homologue deleted on chromosome 10/Akt/forkhead box (IGF-1/PTEN/Akt/FoxO) signaling pathway exerts important physiological impacts on many types of animal cells (Carnero et al., 2008; Reddy et al., 2008) and has been reported to exhibit gastroprotective effects by reducing WRS-induced gastric mucosal cell apoptosis (Nguyen et al., 2007; Zhao et al., 2009). The gastrointestinal tract has been identified as one of the most sensitive target tissues for IGF-1, which has critical biological functions, including the promotion of the differentiation of various cell types, gastrointestinal tract development, and potent anti-apoptotic activity (Warzecha et al., 2006; Karcher et al., 2009; Reyna et al., 2010). In particular, recent studies have demonstrated gastric ulceration-triggered upregulation of IGF-1 expression in gastrointestinal ulcer margins, suggesting that IGF-1 is involved in gastrointestinal repair processes (Cool et al., 2005; Ceranowicz et al., 2009).

The transduction of signals through the IGF-1 receptor triggers a series of multiple intracellular phosphorylation events that prevent cell death (Carroll, 2001). The phosphatidylinositol 3-kinase (PI3K)/Akt pathway predominantly activated by IGF-1 is a strong cell survival cascade. Akt [also called protein kinase B (PKB)] is a serine/threonine protein kinase downstream of PI3K (Song et al., 2005) and an important regulator of cell proliferation, growth, and survival (Cully et al., 2006). To date, 3 members of the Akt family - Akt1, Akt2, and Akt3 - have been isolated. Although they are products of different genes, they are closely related to one another, with up to $80 \%$ amino acid sequence identity. The 3 genes are expressed differentially, with a broader expression for Akt1 and Akt2 and a more restricted expression for Akt3 (Fresno Vara et al., 2004). Previous studies have demonstrated that PI3K/Akt plays critical roles in several gastrointestinal diseases (Coeffier et al., 2011; Tuo et al., 2011). Furthermore, IGF-1 has been reported to reduce WRS-induced gastric mucosal injury by inhibiting the gastric accumulation of neutrophils through the reduction of caspase- 3 activation by PI3K/Akt signaling (Nguyen et al., 2007; Zhao et al., 2009).

$P T E N$ is a tumor-suppressor gene that encodes a dually specific phosphatase that recognizes both lipid and peptide substrates, including phosphatidylinositol $(3,4,5)$-trisphosphate, a product of PI3K. Through its lipid phosphatase activity, PTEN controls Akt signaling and its downstream targets responsible for cell size, cell migration, cell cycle, cell death, and 
focal adhesion formation (Leslie and Downes, 2004). A downstream target of IGF-1/PTEN/ Akt signaling is the $\mathrm{O}$ subfamily of FoxO proteins, which is phosphorylated and thereby inhibited by activated Akt. Four members of the FoxO subfamily - FoxO3a, FoxO1, FoxO4, and FoxO6 - are reported to play key roles in mammalian cells. Phosphorylation of FoxO proteins by Akt results in cytoplasmic retention and inactivation and inhibits the expression of FoxOregulated genes that control the cell cycle, cell death, and cell metabolism. The shuttling of FoxO between the cytoplasm and the nucleus is a key step in cell apoptosis (Burgering and Kops, 2002). Recently, we have demonstrated cell-specific and age-dependent expression patterns of FoxO4 and FoxO3a proteins in the duodenum and their involvement in the development and growth performance of rat duodenum (Huang et al., 2011). We have also found that FoxO4 is a primary transcriptional factor localized in the gastrointestinal tracts of pigs (Zhou et al., 2007). In particular, our previous studies have suggested that the IGF-1/PTEN/Akt/ FoxO signaling pathway plays some role(s) in protecting against ulcers by regulating cellular apoptosis in the development and healing of rat gastric ulcers (Huang et al., 2012).

The aim of the present study was to determine whether the IGF-1/PTEN/PI3K/Akt/ FoxO signaling pathway is involved in protecting against WRS-induced duodenum mucosal lesions. In the WRS rat model, we analyzed the expression and localization of IGF-1, PTEN, Akt, and FoxO with immunohistochemistry and real-time polymerase chain reaction (PCR), respectively. In addition, we investigated cell apoptosis in WRS-induced duodenal mucosal lesions using the terminal deoxynucleotidyl transferase 2'-deoxyuridine, 5'-triphosphate (dUTP) nick-end labeling (TUNEL) method and caspase-3 activity measurement.

\section{MATERIAL AND METHODS}

\section{WRS-induced duodenum mucosal lesion formation in rats}

All experiments were carried out in intact male Sprague-Dawley rats (9-11 weeks old; Qinglongshan Experimental Animal Breeding Farm, Nanjing, China) weighing 200-220 g. All procedures were designed in accordance with generally accepted ethical standards for animal experimentation and the guidelines established by the institutional animal care and use committee of Nanjing Agricultural University. The uniform commercial diets used in the experiment were also purchased from Qinglongshan Experimental Animal Breeding Farm. Regular rat chow and tap water were allowed ad libitum. Rats were housed individually at room temperature $\left(25^{\circ} \mathrm{C}\right)$ with a 12-h: 12 -h light/ dark cycle and humidity of $65-70 \%$. Before each experiment, animals were deprived of food but not water for $24 \mathrm{~h}$. The animals were then placed in a restraint cage and immersed in a water bath $\left(20^{\circ}-22^{\circ} \mathrm{C}\right)$ to the level of the xiphoid process as described elsewhere (Adachi et al., 2011). Some of the animals were killed after 3 and $7 \mathrm{~h}$ of WRS, and the rest were fed normally starting $1 \mathrm{~h}$ later and killed at various time points $(4,8$, and 15 days) after the end of the 7-h WRS treatment. The animals were anesthetized with an intraperitoneal injection of ether. Their duodenums were removed and filled with $2 \mathrm{~mL} 1 \%$ formalin and immersed in $1 \%$ formalin for $24 \mathrm{~h}$.

\section{Assessment of apoptotic cell number}

After transfer through a graded series of alcohol and xylene, the duodenum mucosal samples were embedded in paraffin and sectioned in $7-\mu \mathrm{m}$ thicknesses. The TUNEL method was per- 
formed using an Apoptosis Kit Direct (Beyotime Institute of Biotechnology, Haimen, China) as described elsewhere (Kelly et al., 2003). Briefly, duodenum mucosal cells were counterstained with 2-(4-amidinophenyl)-1H-indole-6-carboxamidine dihydrochloride (Beyotime Institute of Biotechnology) to label all nuclear DNA, and fragmented DNA was end-labeled with fluorescein isothiocyanate-labeled dUTP using terminal transferase. The duodenal mucosa was then observed by using a fluorescence microscope. Sections that were pretreated with DNase I to nick all DNA served as positive controls. For negative controls, dUTP was omitted, resulting in uniformly negative staining. Ten optical fields - approximately 500-1000 cells - were counted in each slide under high power (400X) microscopy, and the number of positive cells per field was expressed as the apoptotic index. These experiments were performed in triplicate with 6 rats per group per experiment.

\section{Measurement of caspase- 3 activity}

The activity of caspase- 3 was detected using a commercially available caspase-3 activity kit (Beyotime Institute of Biotechnology) with Ac-DEVD-pNA (acetyl-Asp-Glu-Val-Asp $p$-nitroanilide) as the colorimetrically specific substrate. In brief, duodenal mucosal samples ( $\mathrm{N}=6$ for each treatment) were weighed and homogenized in lysis buffer containing $10 \mathrm{mM} \mathrm{HEPES} / \mathrm{KOH}$, $\mathrm{pH}$ 7.2, $2 \mathrm{mM}$ ethylenediaminetetraacetic acid, 0.1\% 3-([3-cholamidopropyl]dimethylammonio)1-propanesulfonate, $5 \mathrm{mM}$ dithiothreitol, $1 \mathrm{mM}$ phenylmethyl-sulfonylfluoride, $10 \mu \mathrm{g} / \mathrm{mL}$ aprotinin, and $20 \mu \mathrm{g} / \mathrm{mL}$ leupeptin. The lysate was centrifuged at $20,000 \mathrm{~g}$ for $10 \mathrm{~min}$ at $4^{\circ} \mathrm{C}$, and supernatants were incubated for $7 \mathrm{~h}$ at $37^{\circ} \mathrm{C}$ with $10 \mu \mathrm{L}$ caspase- 3 substrate (Ac-DEVD-pNA, 2 $\mathrm{mM}$ ). Substrate cleavage was measured with a spectrofluorometer at $405 \mathrm{~nm}$ and was corrected as protein content in the lysate. The activity of caspase- 3 was expressed as a value of enzyme activity compared with that in the control (Wang et al., 2010).

\section{Immunohistochemical analysis}

Antibodies for FoxO3A(Cat. No. 9467, Lot 4), FoxO4 (Cat. No. 9472, Lot 1), and total PKB/ Akt (Cat. No. 9292, Lot 1) were purchased from Cell Signaling Technology (Beverly, MA, USA). Antibodies for PTEN (Cat. No. sc-9145, lot C0707) were obtained from Santa Cruz Biotechnology (Santa Cruz, CA, USA). Antibodies for IGF-1 (BA0939) were obtained from Boster Bio-Engineering (Wuhan, China). Streptavidin-biotin complex kits were obtained from BioGenex (San Ramon, CA, USA), and 3,3'-diaminobenzidine tetrachloride was purchased from Sigma Chemical Co. (St. Louis, MO, USA). All other chemicals were purchased commercially and were reagent grade.

After transfer through a graded series of alcohol and xylene, duodenum mucosal samples were embedded in paraffin and sectioned at $7-\mu \mathrm{m}$ thicknesses. The sample sections were mounted on slides and processed for immunohistochemical analysis, which was conducted using a protocol similar to that described in our previous reports (Ding et al., 2010). Briefly, sections were incubated overnight at room temperature with a polyclonal rabbit immunoaffinitypurified antiserum directed against IGF-1 (1:200), PTEN (1:400), total Akt (1:400), FoxO3a (1:400), and FoxO4 (1:500). The specific protein immunoreactivity was visualized with an Elite $\mathrm{ABC}$ Kit and $0.05 \%$ 3,3'-diaminobenzidine tetrachloride in $10 \mathrm{mM}$ phosphate-buffered saline containing $0.01 \% \mathrm{H}_{2} \mathrm{O}_{2}$ for $5 \mathrm{~min}$. The specificity of the antibody was examined using normal rabbit serum instead of the primary antibody. To identify structural components and cell morphology, we counterstained the sections with hematoxylin and mounted them with 
coverslips. Relative levels of immunostaining between animals and cell types were repeated at least 4 times and evaluated by 3 independent observers.

\section{Total RNA isolation and reverse transcription (RT)}

Duodenal mucosa samples were collected and stored in liquid nitrogen until their use for RNA isolation. Total RNA was isolated after homogenizing duodenal mucosa in the Trizol ${ }^{\mathbb{B}}$ reagent (Invitrogen, CA, USA) following the manufacturer protocol. RNA quality was evaluated by examining a portion on an RNA gel. Bands of $18 \mathrm{~S}$ and $28 \mathrm{~S}$ were clear, and slight smearing occurred, indicating that the quality was acceptable. However, the $18 \mathrm{~S}$ band was not as dark as expected, suggesting that some slight RNA degradation had occurred.

RT reactions were performed using RT reagent kits with gDNA Eraser (Takara, Dalian, China). The total reaction volume of $20 \mu \mathrm{L}$ contained $2 \mu \mathrm{L} 5 \mathrm{X}$ gDNA Eraser buffer, $1 \mu \mathrm{L}$ gDNA Eraser, $1 \mu \mathrm{g}$ total RNA, $4 \mu \mathrm{L} 5 \mathrm{X}$ RT buffer, $1 \mu \mathrm{L}$ RT enzyme mix, $1 \mu \mathrm{L}$ RT primer mix and sufficient nuclease-free $\mathrm{H}_{2} \mathrm{O}$. The RT reaction was carried out at $42^{\circ} \mathrm{C}$ for 2 min and $37^{\circ} \mathrm{C}$ for $15 \mathrm{~min}$ and a denaturation step was performed at $85^{\circ} \mathrm{C}$ for $15 \mathrm{~s}$ before the reaction was cooled on ice.

\section{RT-PCR analysis of gene expression}

Quantification of all transcripts was performed with RT quantitative PCR using the ABI 7300 PRISM system (Applied Biosystems, CA, USA). PCR products for 9 genes (IGF-1, PTEN, Akt1, Akt2, Akt3, FoxO3a, FoxO4, and HPRT) were detected with SYBR Green chemistry (Takara). The sequences and GenBank accession Nos. of the primer sets used to amplify the target genes are presented in Table 1. PCRs were run in triplicate in a total volume of $20 \mu \mathrm{L}$ (consisting of SYBR Premix Ex Taq, ROX Reference Dye, $200 \mathrm{nM}$ each of sequence-specific primers, and $100 \mathrm{ng}$ equivalent of cDNA). The amplification conditions were as follows: DNA polymerase activation at $95^{\circ} \mathrm{C}$ for $30 \mathrm{~s}$, followed by 40 amplification cycles at $95^{\circ} \mathrm{C}$ for $5 \mathrm{~s}$ and at $60^{\circ} \mathrm{C}$ for $31 \mathrm{~s}$. At the end of the amplification cycles, a melting curve analysis was performed to verify specific amplification.

\begin{tabular}{|c|c|c|c|}
\hline $\begin{array}{l}\text { Genes and sequence } \\
\text { reference (GenBank No.) }\end{array}$ & Primer sequence & $\begin{array}{l}\text { Size of PCR } \\
\text { product }(b p)\end{array}$ & $\begin{array}{c}\text { Annealing } \\
\text { temperature }\left({ }^{\circ} \mathrm{C}\right)\end{array}$ \\
\hline HPRT (X62085) & $\begin{array}{l}\text { F: 5'-AGTGATGATGAACCAGGTTA-3' } \\
\text { R: 5'-ATTATAGTCAAGGGCATATC-3' }\end{array}$ & 556 & 58.0 \\
\hline IGF-1 (BC086374) & $\begin{array}{l}\text { F: 5'-TGGTGGACGCTCTTCAGTTC-3' } \\
\text { R: 5'-GCTTCAGCGGAGCACAGTAC-3' }\end{array}$ & 168 & 58.0 \\
\hline PTEN (NM031606) & $\begin{array}{l}\text { F: 5'-AGCGTGCGGATAATGACAAG-3' } \\
\text { R: 5'-GGATTTGATGGCTCCTCTACTG-3' }\end{array}$ & 151 & 56.0 \\
\hline Akt1 (NM033230) & $\begin{array}{l}\text { F: 5'-TAGGCATCCCTTCCTTACAG-3' } \\
\text { R: 5'-GCCCGAAGTCCGTTATCT-3' }\end{array}$ & 269 & 58.0 \\
\hline Akt2 (NM017093) & $\begin{array}{l}\text { F: 5'-GAGCCGAGTCCTACAGAATACC-3' } \\
\text { R: 5'-GGCCATCTTTGTCCAGCATA-3' }\end{array}$ & 263 & 58.0 \\
\hline Akt3 (NM031575) & $\begin{array}{l}\text { F: 5'-AACGACCAAAGCCAAATACA-3' } \\
\text { R: 5'-CCCCATTAACATATTCCATCAC-3' }\end{array}$ & 498 & 58.0 \\
\hline FoxO3a (NM001106395) & $\begin{array}{l}\text { F: 5'-TTCGCAACGACCCAATGA-3' } \\
\text { R: 5'-TCCAAGCTCCCATTGAACAT-3' }\end{array}$ & 331 & 57.4 \\
\hline Fox04 (NM001106943) & $\begin{array}{l}\text { F: 5'-GGTGCCCTACTTCAAGGACAA-3' } \\
\text { R: 5'-ATCGGGGTTCAGCATCCA-3' }\end{array}$ & 148 & 58.0 \\
\hline
\end{tabular}


The comparative $\mathrm{CT}$ method was used for relative quantification of target gene expression levels (ABI Prism Sequence Detection System, Applied Biosystems). The quantity of each measured cDNA sample was normalized to the endogenous gene HPRT (a housekeeping gene), and all samples were measured in triplicate. The mean values of the replicate wells for each sample were calculated and divided by the value of $H P R T$ to obtain a normalized value for each transcript.

\section{Statistical analyses}

Statistical analyses were performed using SPSS 17.0. Values are reported as means \pm standard error of the mean. The data were analyzed using one-way analysis of variance and the Fisher protected least significant difference test. A value of $\mathrm{P}<0.05$ was considered to be statistically significant. All experiments were repeated at least 3 times, and representative data are shown.

\section{RESULTS}

\section{Effect of WRS on apoptosis in duodenal mucosa}

Duodenal tissue sections were stained using the TUNEL method to determine the quantity and distribution of apoptotic cells and examine nuclear condensation and fragmentation. Sections exposed to DNase I, which causes DNA fragmentation, showed intense staining of all nuclei and were used as positive controls (data not shown). Sections stained using the described procedure but without the terminal deoxynucleotidyl transferase enzyme showed no staining and were used as negative controls (see Figure 1A-C). As shown in Figure 1, WRS induced an absence of several duodenal villi (see Figure 1D-I). In addition, apoptotic cells were observed in the lamina propria (see Figure 1D-R) after WRS. However, in the duodenal mucosa of non-WRS rats, a small amount of labeling was found, mainly concentrated in the lamina propria of villi (see Figure 1S-U). At higher magnification and resolution, the stained cells showed the characteristic morphology of apoptotic cells. The number of apoptotic cells in the duodenal mucosa of the rats subjected to 3 and $7 \mathrm{~h}$ of WRS were increased by 13 and $32 \%$, respectively, compared with that in the control group (see Figure $2 \mathrm{~A} ; \mathrm{P}>0.05, \mathrm{~N}=6$ ). Subsequently, from the 4 th to the 15 th day after the 7-h WRS treatment, the number of apoptotic cells in the duodenal mucosa decreased gradually (see Figure 2A).

To reconfirm cell apoptosis in the duodenal mucosa of the WRS rat, caspase- 3 activity in the duodenal mucosa was detected using colorimetric analysis. As shown in Figure 2B, caspase- 3 activity in the duodenal mucosa after 3 and $7 \mathrm{~h}$ of WRS was also time-dependently enhanced by 23 and $31 \%$ compared with that in the control group. However, on the 4th, 8th, and 15th day after the 7-h WRS treatment, caspase-3 activity decreased gradually compared with that in the 7-h WRS group.

\section{Immunohistochemical localization of IGF-1, PTEN, total Akt, FoxO3a, and FoxO4 in the duodenal mucosa of rats after WRS}

To assess the localization of IGF-1, PTEN, total Akt, FoxO3a, and FoxO4 in rat duodenal mucosa, we stained sections from non-WRS and WRS rat duodenal mucosa with specific antibodies against these proteins. In normal rat duodenal mucosa, PTEN (see 
TUNEL
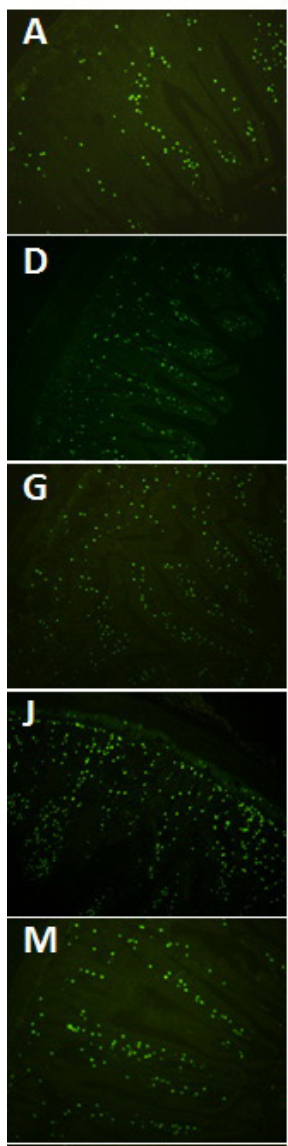

$\mathbf{P}$

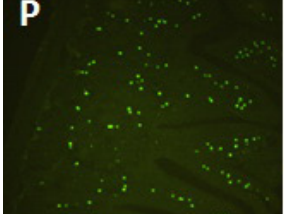

S

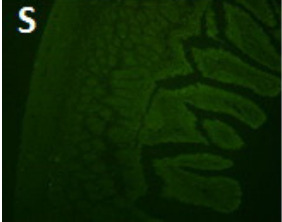

DAPI

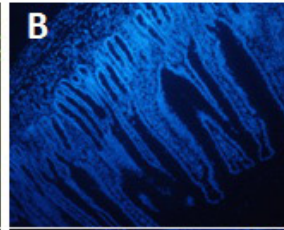

$\mathbf{E}$
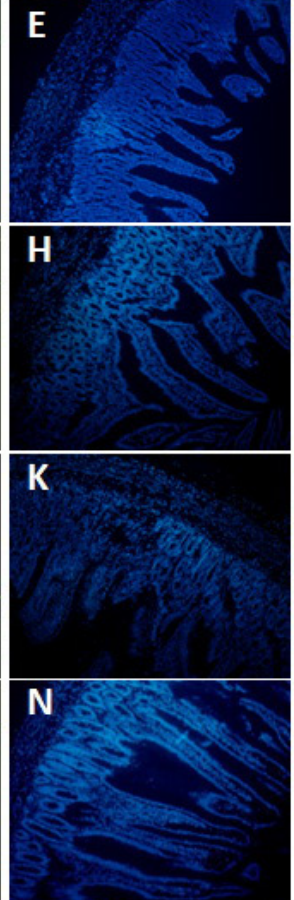

$\mathbf{Q}$
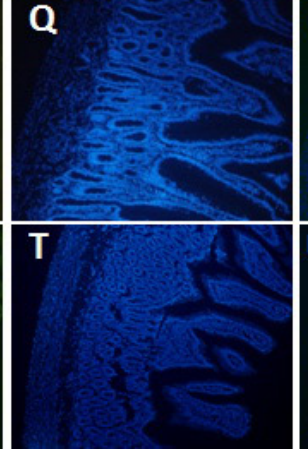

Merge
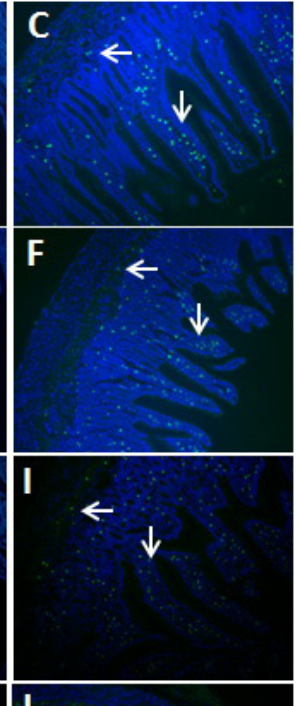

$\mathbf{L}$

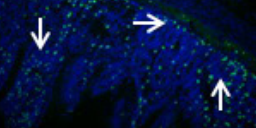

O

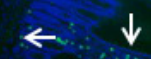

$\mathbf{R}$
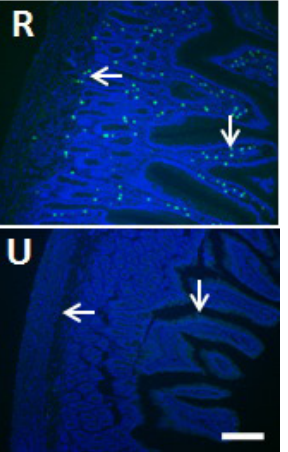

Figure 1. Effect of water immersion and restraint stress (WRS) on apoptostic cells in the duodenal mucosa. First, sections of rat duodenal mucosa were stained using the TUNEL method, and sections were then counterstained with DAPI to label all nuclei. Blue color $=$ DAPI-stained nuclei. Green color $=$ TUNEL-positive cells. The figures indicate non-WRS (A-C), $3 \mathrm{~h}$ of WRS (D-F), $7 \mathrm{~h}$ of WRS (G-I), 4 days after WRS (J-L), 8 days after WRS (M-O), and 15 days after WRS (P-R). Sections stained by the previous procedure but without use of the TdT enzyme showed no staining and were used as negative controls $(\mathbf{S}-\mathbf{U}) . \rightarrow=$ muscularis mucosa. $\downarrow=$ duodenal villi. Bar $=50 \mu \mathrm{m}$. 
A

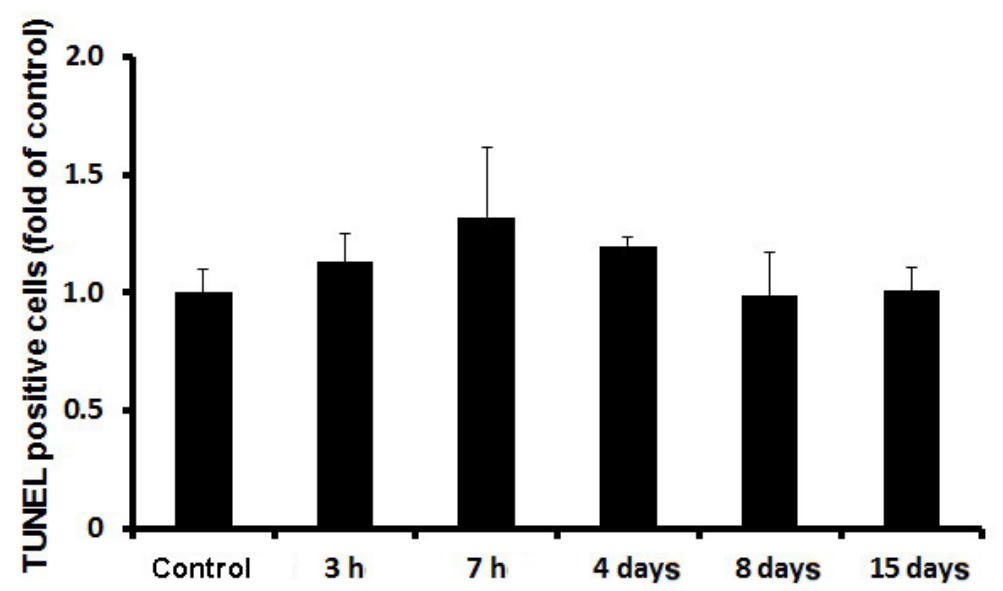

B

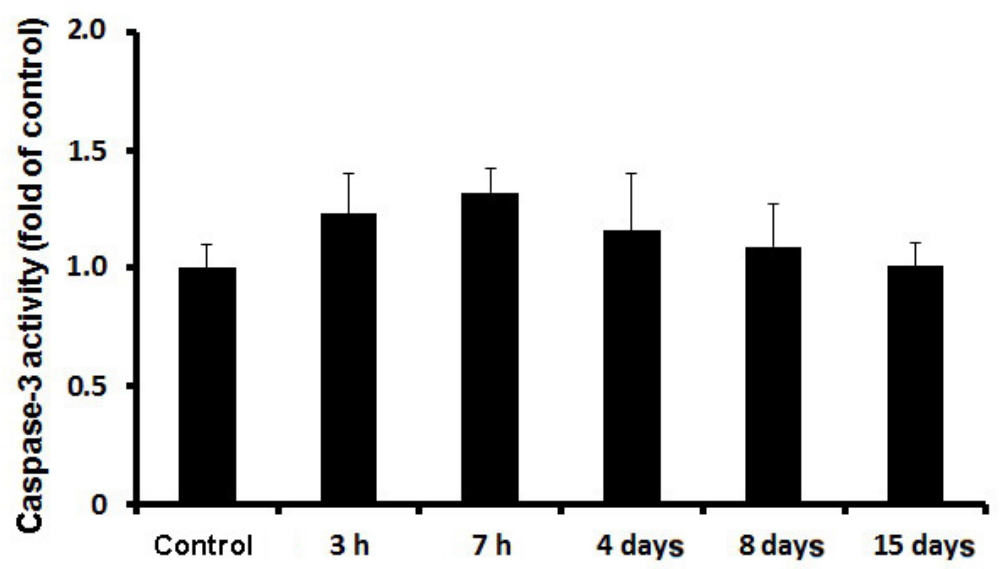

Figure 2. Effect of water immersion and restraint stress on number of TUNEL-positive cells in duodenal mucosa (A) and caspase-3 activity in duodenal mucosa (B) in rats. Data (fold of control) represent means $\pm \mathrm{SEM}$.

Figure 3B) was found mainly in the cellular cytoplasm of the duodenal glands (see Figure 3C) and the lamina propria of villi (see Figure 3D). In addition, IGF-1 (see Figure 3E and F) and total Akt (see Figure 3G and $\mathrm{H}$ ) were observed in the cellular cytoplasm of the duodenal glands. Total Akt (see Figure $3 \mathrm{G}$ and $\mathrm{H}$ ) was also found in the cellular cytoplasm of the myenteric plexus. FoxO3a (see Figure 3I and J) and FoxO4 (see Figure 3K and L) were primarily concentrated in the cellular cytoplasm of the lamina propria. Notably, in duodenal mucosa of rats subjected to WRS, PTEN (see Figure 3B and D), FoxO3a (see Figure 3I and J), and FoxO4 (see Figure 3K and L) were also localized in the cellular cytoplasm of the lamina propria of restituted villi. However, the expression patterns of IGF-1 (see Figure 3E and F) and total Akt (see Figure 3G and H) were unchanged in the duodenal mucosa of rats after WRS compared with those of normal rats. 


\section{Relative expression of IGF-1, PTEN, Akt1, Akt2, Akt3, FoxO3a, and FoxO4 in the gastric mucosa of rats after WRS}

Expression levels of selected genes were analyzed using RT-PCR. Amplification products were identified through melting curve profile analysis and confirmed with gel electrophoresis and sequencing. The data showed the relative transcript of each target gene normalized to HPRT. The real-time RT-PCR analyses of transcripts of $168 \mathrm{bp} I G F-1,151 \mathrm{bp}$ PTEN, 269 bp Akt1, 263 bp Akt2, 498 bp Akt3, 331 bp FoxO3a, 148 bp FoxO4, and 556 bp $H P R T$ are shown in Figure 4. All selected genes were transcriptionally active. After 3 and 7 $\mathrm{h}$ of WRS, messenger RNA (mRNA) transcript levels of IGF-1 (see Figure 4A), PTEN (see Figure 4A), FoxO3a (see Figure 4C), and FoxO4 (see Figure 4C) in rats subjected to WRS showed no significant difference compared with those in the non-WRS group ( $\mathrm{P}>0.05, \mathrm{~N}$ $=6$ ). In addition, no significant difference was found in PTEN (see Figure 4A) mRNA transcript levels among the 4 th, 8 th, and 15 th days after $7 \mathrm{~h}$ of WRS $(\mathrm{P}>0.05, \mathrm{~N}=6)$. However, PTEN (see Figure 4A) mRNA transcript levels at these stages were greater than those of the non-WRS group $(\mathrm{P}<0.05, \mathrm{~N}=6)$.
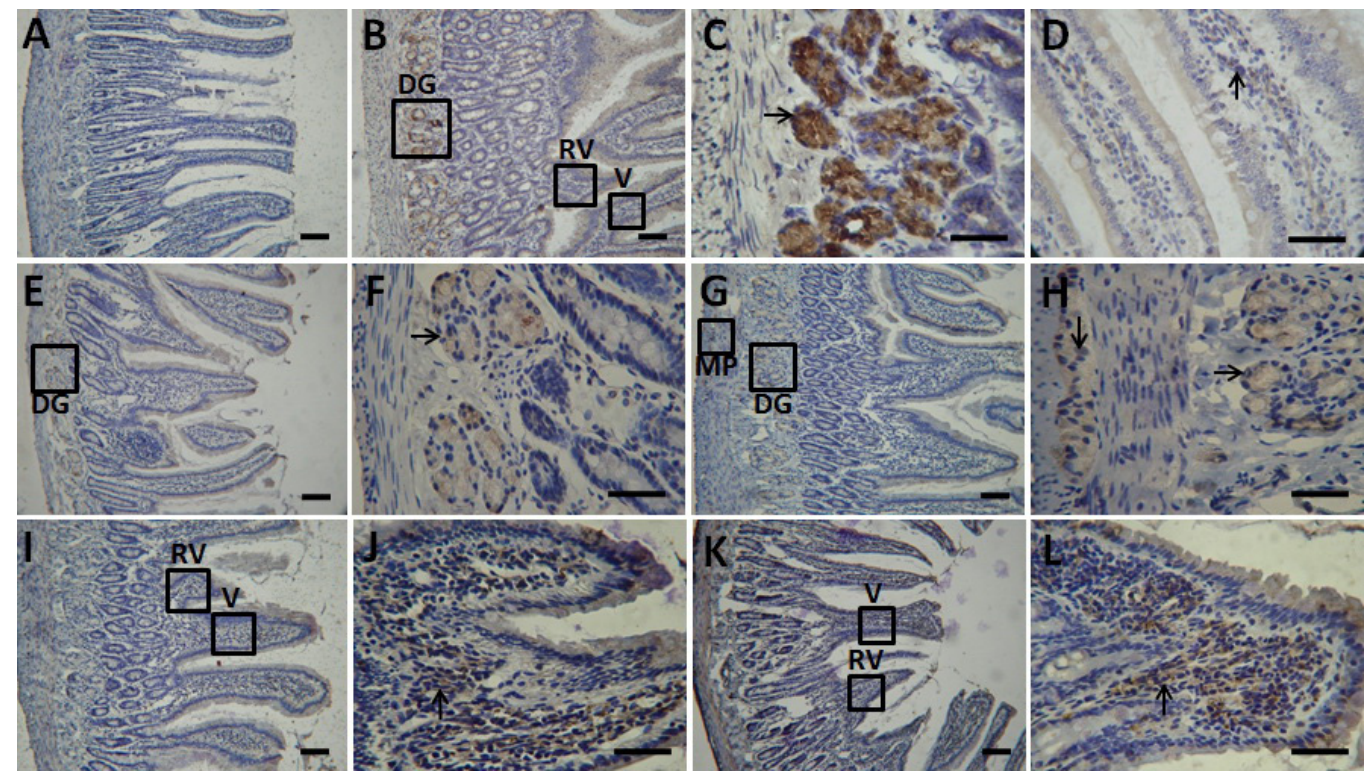

Figure 3. Immunohistochemical localization of IGF-1, PTEN, total Akt, FoxO3a, and FoxO4 in the duodenal mucosa of rats after water immersion and restraint stress. The immunohistochemical signals appear brown and the counterstained background appears blue in color. The figures indicate immunohistochemical localization of PTEN (B-D); immunohistochemical localization of IGF-1 (E and F); immunohistochemical localization of total Akt (G and $\mathbf{H}$ ); immunohistochemical localization of FoxO3a (I and $\mathbf{J})$, and immunohistochemical localization of FoxO4 ( $\mathbf{K}$ and $\mathbf{L}$ ). In control sections, normal albumin bovine was used instead of primary antibody (A). DG $=$ duodenal gland; $\mathrm{V}=$ villi; $\mathrm{RV}=$ regenerated villi; $\mathrm{MP}=$ myenteric plexus; $\downarrow=$ myenteric plexus; $\rightarrow=$ duodenal gland; $\uparrow=$ lamina propria. $\mathrm{Bar}=50 \mu \mathrm{m}$. 


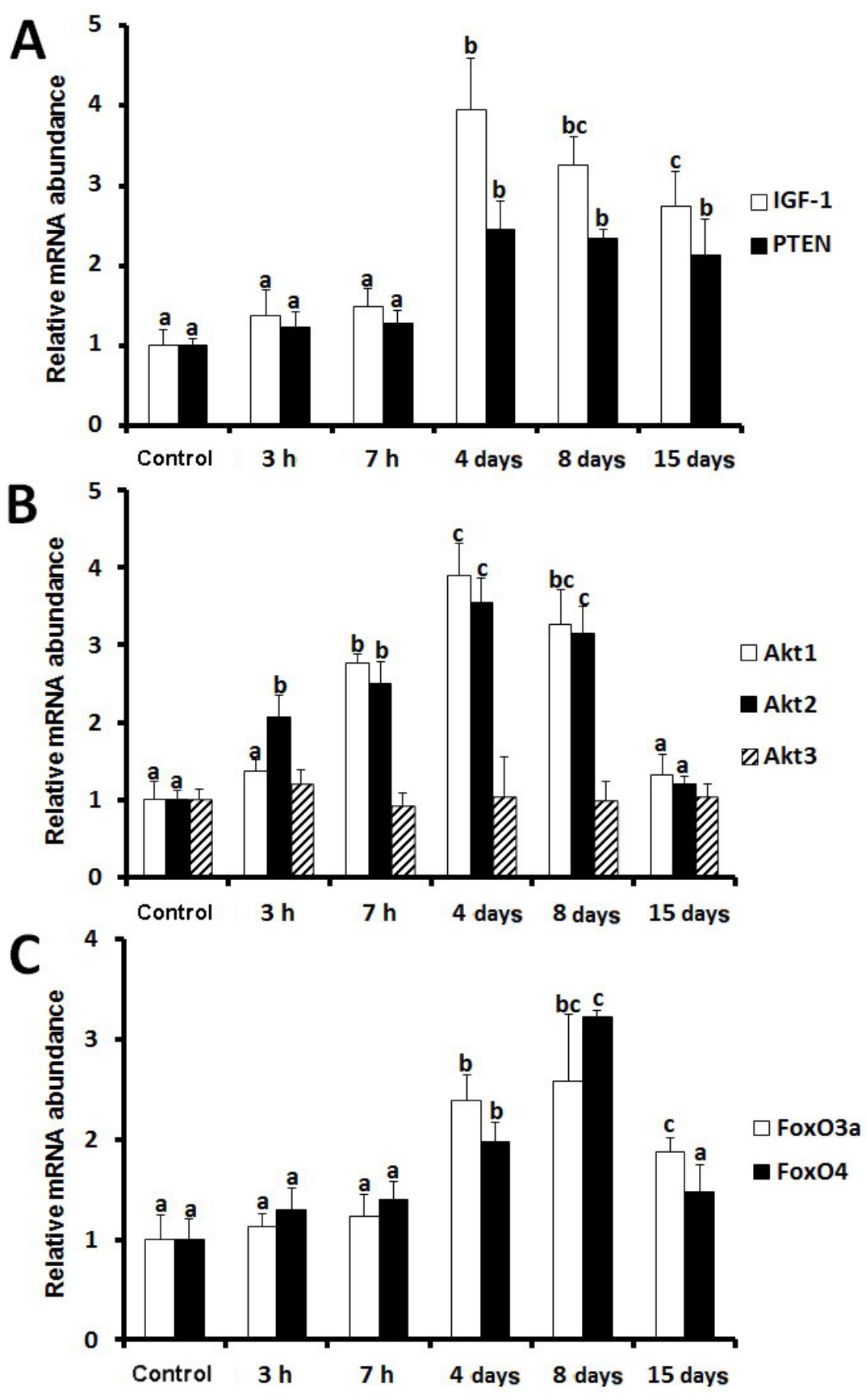

Figure 4. Relative expressions of IGF-1, PTEN, Akt1, Akt2, Akt3, FoxO3a, and FoxO4 in the duodenal mucosa of rats after water immersion and restraint stress. The figures indicate IGF-1 and PTEN(A);Akt1, Akt2 and Akt3 (B); FoxO3a and FoxO4 (C). Different letters above the bars indicate a statistically significant difference in the same gene $(\mathrm{P}<0.05, \mathrm{~N}=5)$ between treatment groups. 
In duodenal mucosa of rats after WRS, mRNA transcript levels of $I G F-1$ (see Figure 4A), Akt1 (see Figure 4B), and Akt2 (see Figure 4B) were upregulated, with a peak 4 days after $7 \mathrm{~h}$ of WRS. The mRNA transcript levels of $A k t 1$ and $A k t 2$ returned to near baseline 15 days after $7 \mathrm{~h}$ of WRS. However, the mRNA transcript levels of $I G F-1$ (see Figure 4A) in the WRS groups were still greater than that in the non-WRS group $(\mathrm{P}<0.05, \mathrm{~N}=6)$. Similarly, mRNA transcript levels of FoxO3a (see Figure 4C) and FoxO4 (see Figure 4C) were also upregulated after WRS, peaking 8 days after $7 \mathrm{~h}$ of WRS. The FoxO $3 a$ mRNA transcript level (see Figure $4 \mathrm{C})$ was still greater than that in the non-WRS group 15 days after $7 \mathrm{~h}$ of WRS $(\mathrm{P}<0.05, \mathrm{~N}$ $=6$ ). The FoxO4 mRNA transcript level (see Figure 4C) returned to near baseline levels, and $A k t 3$ (see Figure 4B) mRNA transcript levels in rats subjected to WRS were unchanged compared with that of the non-WRS group $(\mathrm{P}>0.05, \mathrm{~N}=6)$.

\section{DISCUSSION}

The WRS rat has long been used as a model of gastroduodenal mucosal lesions (Wang and Johnson, 1992; Bogdarin et al., 2005; Adachi et al., 2011). As shown in previous studies, WRS results in microscopic damage evidenced by a nearly complete absence of villi. Significant macroscopic lesions are absent after stress. Mucosal repair is evident $12 \mathrm{~h}$ after stress and is almost complete at $24 \mathrm{~h}$, although the restituted villi are short (Wang and Johnson, 1992). In addition, apoptosis plays an important role in the maintenance of normal gastrointestinal homeostasis and mucosal integrity (Sun et al., 1998). Recent studies have demonstrated that apoptosis is critically involved in gastric ulceration $24 \mathrm{~h}$ after ulcer induction (Konturek et al., 2001). Caspases are causative enzymes that induce apoptosis and are always present in intact cells, playing key roles in the pathogenesis of tissue injury by activating neutrophils. All known stimuli that induce apoptosis initiate events that culminate in caspase activation (Creagh et al., 2003). Previous studies have reported that IGF-1 and capsaicin administration to rats markedly reduces WRS-induced gastric mucosal injury by limiting the gastric accumulation of neutrophils through inhibition of caspase-3 activation (Zhao et al., 2009). In our present study, we found that TUNEL-positive cells are concentrated mainly in the lamina propria of the duodenal mucosa. In addition, WRS increased both caspase- 3 activity and the number of TUNEL-positive cells after 3 and $7 \mathrm{~h}$ of WRS. Subsequently, caspase-3 activity and the number of TUNEL-positive cells gradually returned to near baseline levels, suggesting that apoptosis played a role in the duodenal mucosa of rats after WRS.

The IGF-1/PTEN/Akt/FoxO signaling pathway plays some critical roles in the regulation of survival, growth, differentiation, and migration in many cell types and tissues (Reddy et al., 2008). In particular, our previous study has demonstrated that the IGF-1/PTEN/Akt/FoxO signaling pathway is involved in protecting against ulcer through regulation of cellular apoptosis in the development and healing of rat gastric ulcers. To confirm whether the IGF-1/PTEN/ $\mathrm{Akt} / \mathrm{FoxO}$ signaling pathway is involved in the responses of the duodenal mucosa of rats subjected to WRS, we detected the localization and expression of IGF-1, PTEN, Akt, and FoxO.

Our results indicated that the localization of IGF-1 was unchanged in the duodenal mucosa of rats after WRS compared with that in non-WRS rats. IGF-1 was mainly observed in the cellular cytoplasm of duodenal glands. IGF-1 has also reportedly been discernible in the muscularis externa of the duodenum in the one-humped camel (Al Haj Ali et al., 2003). We suspected species-specific expression of IGF-1 in the duodenum. mRNA transcript levels of IGF-1 were 
upregulated, peaking at 4 days after $7 \mathrm{~h}$ of WRS. In the gastrointestinal tract, IGF-1 is secreted by salivary and other exocrine glands. Gastric ulceration reportedly triggers a several-fold increase in IGF-1 expression in ulcer margins (Coerper et al., 2001; Nguyen et al., 2007). Related findings have also indicated that IGF-1 is upregulated in injured skin, bone, and brain (Nguyen et al., 2007). In particular, IGF-1 reduces tissue injury by preventing cell death in animal models of renal ischemia/reperfusion. Among the various actions of IGF-1, its anti-apoptotic activity plays an important role in the reduction of ischemia/reperfusion-induced tissue injury by attenuating inflammatory responses (Harada et al., 2007). In addition, previous studies have demonstrated that IGF-1 has an essential role in gastrointestinal tract growth and development (Georgiev et al., 2003; Warzecha et al., 2006; Karcher et al., 2009; Mullen et al., 2011) and is an important growth factor in gut maintenance (Ryan and Costigan, 1993). Accordingly, our results suggested that IGF-1 was critically involved in the duodenal mucosa of rats after WRS.

As an important downstream effector of IGF-1, the PI3K/Akt signaling pathway is associated with pharmacotherapy through upregulation of cell proliferation in duodenal mucosa (Coeffier et al., 2011; Tuo et al., 2011). In addition, Nguyen et al. (2007) have found that upregulation of IGF-1 in gastric ulcer margins enhanced gastric ulcer healing by promoting cell re-epithelization and proliferation via the PI3K pathway (Nguyen et al., 2007). Furthermore, IGF-1 has been reported to reduce WRS-induced gastric mucosal injury by reducing gastric accumulation of neutrophils through inhibition of caspase-3 activation by PI3K/Akt signaling (Zhao et al., 2009). In the present study, total Akt was observed in the cellular cytoplasm of the duodenal glands and myenteric plexus. WRS triggered increases in Akt1 and Akt2 mRNA expression in rat duodenal mucosa, with a peak at 4 days after $7 \mathrm{~h}$ of WRS. mRNA transcript levels of $A k t 3$ were unchanged in the duodenal mucosa of rats after WRS compared with that of the non-WRS group. These results were consistent with our previous studies on WRS-induced gastric ulcers in rats (Huang et al., 2012), suggesting that Akt1 and Akt2 might participate in the regulation of cell proliferation in the duodenal mucosa of rats after WRS.

$P T E N$ is an important tumor suppressor that controls Akt signaling. Its downstream targets are responsible for regulating many physiologically and pathologically significant processes, such as cellular proliferation, survival, growth, and motility (Leslie and Downes, 2004). Many researchers have concentrated on PTEN in gastric cancer (Liu et al., 2011; Wang et al., 2011; Xiong et al., 2011). The present study indicated that PTEN was found mainly in the cellular cytoplasm of the duodenal glands and lamina propria of villi. In the duodenal mucosa of rat subjected to WRS, PTEN was also detected in the cellular cytoplasm of the lamina propria of restituted villi. In addition, PTEN mRNA transcript levels of rats 4, 8, and 15 days after $7 \mathrm{~h}$ of WRS were greater than those of rats in the non-WRS group. Wang et al. (2011) have revealed that caspase- 3 activity is related to the upregulation of PTEN in human gastric cancer MGC-803 cells. Our previous studies also demonstrated that PTEN is upregulated in WRS-induced gastric ulcers (Huang et al., 2012). Therefore, it was reasonable to suspect that PTEN may be involved in the regulation of cell apoptosis through the PI3K/Akt pathway in the duodenal mucosa of rats after WRS.

FoxO1, FoxO3a, and FoxO4 are all targets of the IGF-1/PTEN/Akt pathway and participate in several physiologic processes including cell proliferation, apoptosis, stress resistance, differentiation, and metabolism (Nakae et al., 2002). Our previous studies have found that FoxO3a and FoxO4 are the primary forkhead transcriptional factors localized to the gastrointestinal tract (Zhou et al., 2007; Huang et al., 2011). Liu et al. (2008) have shown that 
FoxO1 mRNA is expressed at lower levels in duodenal subcutaneous adipose tissue than in other tissues in pigs. Therefore, in the present study, we detected the localization and expression of FoxO3a and FoxO4 in the duodenal mucosa of rats after WRS. The results indicated that FoxO3a and FoxO4 were primarily concentrated in the cellular cytoplasm of the lamina propria. PTEN was also detected in the cellular cytoplasm of the lamina propria of restituted villi in rats after WRS. At the same time, mRNA transcript levels of FoxO3a and FoxO4 were upregulated, peaking 8 days after $7 \mathrm{~h}$ of WRS. This result was similar to that in rats with WRS-induced gastric ulcers (Huang et al., 2012). Phosphorylation of FoxO proteins by Akt results in cytoplasmic retention and inactivation, which in turn inhibits the expression of FoxO-regulated genes that control the cell cycle, cell death, and cell metabolism. The shuttling of FoxOs between the cytoplasm and the nucleus is a key step in apoptosis (Burgering and Kops, 2002). Therefore, FoxO3a and FoxO4 may also play some roles related to cell apoptosis regulation in the duodenal mucosa of rats after WRS. In conclusion, these observations raised the possibility that the IGF-1/PTEN/Akt/FoxO signaling pathway regulates cellular apoptosis in the duodenal mucosa of rats after WRS.

\section{ACKNOWLEDGMENTS}

Research supported by the National Nature Science Foundation of China (\#31172206) and a Grant-in-Aid for Innovative Training of Doctoral Students in Jiangsu Province of China (\#CXLX11-0699).

\section{REFERENCES}

Adachi M, Horiuchi G, Ikematsu N, Tanaka T, et al. (2011). Intragastrically administered lysophosphatidic acids protect against gastric ulcer in rats under water-immersion restraint stress. Dig. Dis. Sci. 56: 2252-2261.

Al Haj Ali M, Mensah-Brown E, Chandranath SI, Adeghate E, et al. (2003). Distribution of insulin like growth factor-1 (IGF1) and its receptor in the intestines of the one-humped camel (Camelus dromedarius). Growth Factors 21: 131-137.

Bogdarin I, Potekhin PP, Kozlov DV and Shirokova NI (2005). Efficacy of the new collection of herbs at stressful experimental sharp ulcer defects of the gastroduodenal zone. Eksp. Klin. Gastroenterol. 74-8, 102.

Burgering BM and Kops GJ (2002). Cell cycle and death control: long live Forkheads. Trends Biochem. Sci. 27: 352-360.

Carnero A, Blanco-Aparicio C, Renner O, Link W, et al. (2008). The PTEN/PI3K/AKT signalling pathway in cancer, therapeutic implications. Curr. Cancer Drug Targets. 8: 187-198.

Carroll PV (2001). Treatment with growth hormone and insulin-like growth factor-I in critical illness. Best. Pract. Res. Clin. Endocrinol. Metab. 15: 435-451.

Ceranowicz P, Warzecha Z, Dembinski A, Sendur R, et al. (2009). Treatment with ghrelin accelerates the healing of acetic acid-induced gastric and duodenal ulcers in rats. J. Physiol. Pharmacol. 60: 87-98.

Coeffier M, Claeyssens S, Bensifi M, Lecleire S, et al. (2011). Influence of leucine on protein metabolism, phosphokinase expression, and cell proliferation in human duodenum1,3. Am. J. Clin. Nutr. 93: 1255-1262.

Coerper S, Wolf S, von KS, Thomas S, et al. (2001). Insulin-like growth factor I accelerates gastric ulcer healing by stimulating cell proliferation and by inhibiting gastric acid secretion. Scand. J. Gastroenterol. 36: 921-927.

Cool JC, Dyer JL, Xian CJ, Butler RN, et al. (2005). Pre-treatment with insulin-like growth factor-I partially ameliorates 5-fluorouracil-induced intestinal mucositis in rats. Growth Horm. IGF Res. 15: 72-82.

Creagh EM, Conroy H and Martin SJ (2003). Caspase-activation pathways in apoptosis and immunity. Immunol. Rev. 193: 10-21.

Cully M, You H, Levine AJ and Mak TW (2006). Beyond PTEN mutations: the PI3K pathway as an integrator of multiple inputs during tumorigenesis. Nat. Rev. Cancer 6: 184-192.

Ding W, Wang W, Zhou B, Zhang W, et al. (2010). Formation of primordial follicles and immunolocalization of PTEN, PKB and FOXO3A proteins in the ovaries of fetal and neonatal pigs. J. Reprod. Dev. 56: 162-168.

Fresno Vara JA, Casado E, de Castro J, Cejas P, et al. (2004). PI3K/Akt signalling pathway and cancer. Cancer Treat. 
Rev. 30: 193-204.

Georgiev IP, Georgieva TM, Pfaffl M, Hammon HM, et al. (2003). Insulin-like growth factor and insulin receptors in intestinal mucosa of neonatal calves. J. Endocrinol. 176: 121-132.

Harada N, Okajima K, Kurihara H and Nakagata N (2007). Stimulation of sensory neurons by capsaicin increases tissue levels of IGF-I, thereby reducing reperfusion-induced apoptosis in mice. Neuropharmacology 52: 1303-1311.

Huang P, Zhou ZQ, Huang RH, Zhou B, et al. (2011). Age-dependent expression of forkhead box O proteins in the duodenum of rats. J. Zhejiang. Univ. Sci. B 12: 730-735.

Huang P, Zhou ZR, Wang H, Wei QW, et al. (2012). Effect of the IGF-1/PTEN/Akt/FoxO signaling pathway on the development and healing of water immersion and restraint stress-induced gastric ulcers in rats. Int. J. Mol. Med. 30: 650-658.

Karcher DM, Fleming-Waddell JN and Applegate TJ (2009). Developmental changes in insulin-like growth factor (IGF)-I and -II mRNA abundance in extra-embryonic membranes and small intestine of avian embryos. Growth Horm. IGF Res. 19: 31-42.

Kelly KJ, Sandoval RM, Dunn KW, Molitoris BA, et al. (2003). A novel method to determine specificity and sensitivity of the TUNEL reaction in the quantitation of apoptosis. Am. J. Physiol. Cell Physiol. 284: C1309-C1318.

Konturek PC, Brzozowski T, Duda A, Kwiecien S, et al. (2001). Epidermal growth factor and prostaglandin E(2) accelerate mucosal recovery from stress-induced gastric lesions via inhibition of apoptosis. J. Physiol. Paris 95: 361-367.

Leslie NR and Downes CP (2004). PTEN function: how normal cells control it and tumour cells lose it. Biochem. J. 382: 1-11.

Liu X, Guo WJ, Zhang XW, Cai X, et al. (2011). Cetuximab enhances the activities of irinotecan on gastric cancer cell lines through downregulating the EGFR pathway upregulated by irinotecan. Cancer Chemother. Pharmacol. 68: 871-878.

Liu Y, Wang Y, Shan T, Guo J, et al. (2008). The tissue-specific and developmental expression patterns of the forkhead transcription factor FoxO1 gene in pigs. J. Anim. Feed Sci. 17: 182-190.

Mullen MP, Lynch CO, Waters SM, Howard DJ, et al. (2011). Single nucleotide polymorphisms in the growth hormone and insulin-like growth factor-1 genes are associated with milk production, body condition score and fertility traits in dairy cows. Genet. Mol. Res. 10: 1819-1830.

Nakae J, Biggs WH, III, Kitamura T, Cavenee WK, et al. (2002). Regulation of insulin action and pancreatic beta-cell function by mutated alleles of the gene encoding forkhead transcription factor Foxo1. Nat. Genet. 32: 245-253.

Nguyen T, Chai J, Li A, Akahoshi T, et al. (2007). Novel roles of local insulin-like growth factor-1 activation in gastric ulcer healing: promotes actin polymerization, cell proliferation, re-epithelialization, and induces cyclooxygenase-2 in a phosphatidylinositol 3-kinase-dependent manner. Am. J. Pathol. 170: 1219-1228.

Reddy P, Liu L, Adhikari D, Jagarlamudi K, et al. (2008). Oocyte-specific deletion of Pten causes premature activation of the primordial follicle pool. Science 319: 611-613.

Reyna XF, Montoya HM, Castrellon VV, Rincon AM, et al. (2010). Polymorphisms in the IGF1 gene and their effect on growth traits in Mexican beef cattle. Genet. Mol. Res. 9: 875-883.

Ryan J and Costigan DC (1993). Determination of the histological distribution of insulin like growth factor 1 receptors in the rat gut. Gut 34: 1693-1697.

Song G, Ouyang G and Bao S (2005). The activation of Akt/PKB signaling pathway and cell survival. J. Cell Mol. Med. 9: 59-71.

Sun Z, Wang X, Wallen R, Deng X, et al. (1998). The influence of apoptosis on intestinal barrier integrity in rats. Scand. J. Gastroenterol. 33: 415-422.

Tuo B, Wen G, Song P, Xu J, et al. (2011). Genistein stimulates duodenal $\mathrm{HCO}(3)(-)$ secretion through PI3K pathway in mice. Eur. J. Pharmacol. 651: 159-167.

Wang JY and Johnson LR (1991). Polyamines and ornithine decarboxylase during repair of duodenal mucosa after stress in rats. Gastroenterology 100: 333-343.

Wang JY and Johnson LR (1992). Luminal polyamines substitute for tissue polyamines in duodenal mucosal repair after stress in rats. Gastroenterology 102: 1109-1117.

Wang W, Xu J, Li L, Wang P, et al. (2010). Neuroprotective effect of morroniside on focal cerebral ischemia in rats. Brain Res. Bull. 83: 196-201.

Wang XT, Xie YB and Xiao Q (2011). Lentivirus-mediated RNA interference targeting E2F-1 inhibits human gastric cancer MGC-803 cell growth in vivo. Exp. Mol. Med. 43: 638-645.

Warzecha Z, Dembinski A, Ceranowicz P, Dembinski M, et al. (2006). Influence of ghrelin on gastric and duodenal growth and expression of digestive enzymes in young mature rats. J. Physiol. Pharmacol. 57: 425-437.

Xiong X, Ren HZ, Li MH, Mei JH, et al. (2011). Down-regulated miRNA-214 induces a cell cycle G1 arrest in gastric cancer cells by up-regulating the PTEN protein. Pathol. Oncol. Res. 17: 931-937.

Zhao J, Harada N, Sobue K, Katsuya H, et al. (2009). Insulin-like growth factor-I reduces stress-induced gastric mucosal injury by inhibiting neutrophil activation in mice. Growth Horm. IGF Res. 19: 136-145.

Zhou ZQ, Wang T, Pan LM, Huang RH, et al. (2007). FoxO4 is the main forkhead transcriptional factor localized in the gastrointestinal tracts of pigs. J. Zhejiang Univ. Sci. B 8: 39-44.

Genetics and Molecular Research 11 (4): 4775-4788 (2012) 